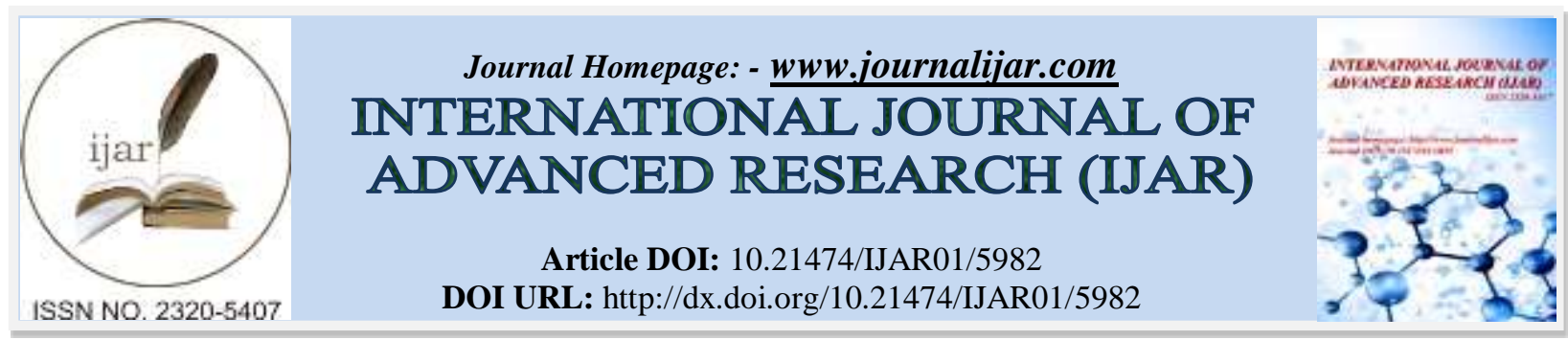

RESEARCH ARTICLE

\title{
PAEONIA EMODI: A REVIEW OF MULTIPURPOSE WILD EDIBLE MEDICINAL PLANT OF WESTERN HIMALAYA.
}

\author{
"Praveen Joshi ${ }^{1}$, Prem Prakash ${ }^{1}$, V. K. Purohit ${ }^{2}$ and V. Bahuguna ${ }^{3}$. \\ 1. Govt. Post Graduate College, Dwarahat, Almora, Uttarakhand, India. \\ 2. HAPPRC, H.N.B.Garhwal University (A Central University), Srinagar Garhwal, Uttarakhand, India. \\ 3. College of applied \& life science, Uttaranchal University.
}

\section{Manuscript Info}

\section{Manuscript History}

Received: 06 October 2017

Final Accepted: 08 November 2017

Published: December 2017

\begin{abstract}
Paeonia emodi Wallich ex Royle (Paeoniaceae), a perennial herb commonly known as 'Chandra' or 'Dhandru', is distributed in Indian Himalayan Region (IHR), from 1800 and 3000 m asl. This study was performed to investigate traditional uses of Paeonia emodi in Western Himalayan region. Paeonia emodi is used in traditional medicine in its home range to treat amongst others diarrhea, high blood pressure, congestive heart failure, palpitation, asthma and arteriosclerosis. Extract of the root stabilizes heartbeat rates, relaxes the airways and reduces blood clotting. Aerial part of the plant was being used for chunks processing. Dried material after processing was used for vegetable preparation, which is highly useful for the diabetic patient. The study will contribute to ensuring proper utilization, commercialization, and conservation as well as the sustainable uses of this species. It has very high medicinal values used in the cure of many domestic issues.
\end{abstract}

Copy Right, IJAR, 2017,. All rights reserved.

\section{Introduction:-}

Himalaya is well known for its rich biodiversity in medicinal and aromatic plants. Owing to its unique geographical setup, topography and undulant landscape the climatic conditions varied along with altitudinal gradients which attribute diversified ecological habitat ranging from tropical forest, grassland to alpine meadows with vast and diverse natural resources. Unfortunately, some of the natural resources are unscientifically exploited for various purposes particularly medicinal plants. Interest in the exploitation of medicinal and aromatic plants as pharmaceutical, herbal remedies, flavouring, perfumes and cosmetics and other natural products has greatly increased in the recent years (Ayensu, 1996; Kumar et al., 2000). Medicinal plants of the western Himalayan region offer alternative remedies with tremendous opportunities. It not only provides access and affordable medicine to the poor people; besides they can also generate income and employment for the developing countries (Rao and Arora, 2003).

Thus, the medicinal plants have been used by humans from prehistoric times. However, relatively few medicinal and aromatic plant species have been brought into cultivation worldwide and most of these species continue to be harvested from their native habitats (Gupta and Chadha, 1995; Gautam et al., 1998). In India alone, less than 10\% of the medicinal plants traded in the country are cultivated, about $90 \%$ are collected from the wild, very often in destructive and unsustainable manner (Natesh, 2000). Most of the medicinal plants are being extracted for drug and pharmaceutical industries, traditional use and research purposes from wild populations. These activities adversely 
affected the existence of a number of plants, particularly those of high commercial value. Further, the developmental activities in the higher Himalayan region without rehabilitation work of these valuable resources, the original populations of many of them have been vanishing. However, in the Himalayan region, several medicinal plant species found and Paeonia emodi is one of them. The species has been cited as vulnerable (CAMP, 1998; Samant et al; 1998) and near endemic (Dhar and Samant; 1993) to Indian Himalayan Region (IHR). The comparatively low density and localized distribution, reveals that this species is on the edge of threat status (Rawat et al; 2010) and need to be conserved.

It is a narrative review for the species Paeonia emodi found in Western Himalayan region and is very high medicinal value for the local residents. For this selected studies are compared and summarized on the basis of the author's experience, existing theories and models. Results are based on a qualitative rather than a quantitative level. The literature regarding P.emodi has been taken from different research papers, textbooks, internet bibliographic database and websites.

The genus Paeonia belongs to the family Paeoniaceae, also known by the name of "Ranunculaceae" has total 40 species (including shrubs and perennial herbs) distributed all over the world (Uddin et al., 2013), in which 10 species are found in the Pan-Himalayas (Hong D.Y., 2010). Tree paeony has long been called King of Flowers in China and the herbaceous paeony was called Queen of flowers due to the beauty of its flowers and medicinal repute in ancient Greece. It is also grown for ornaments in gardens on the hills.
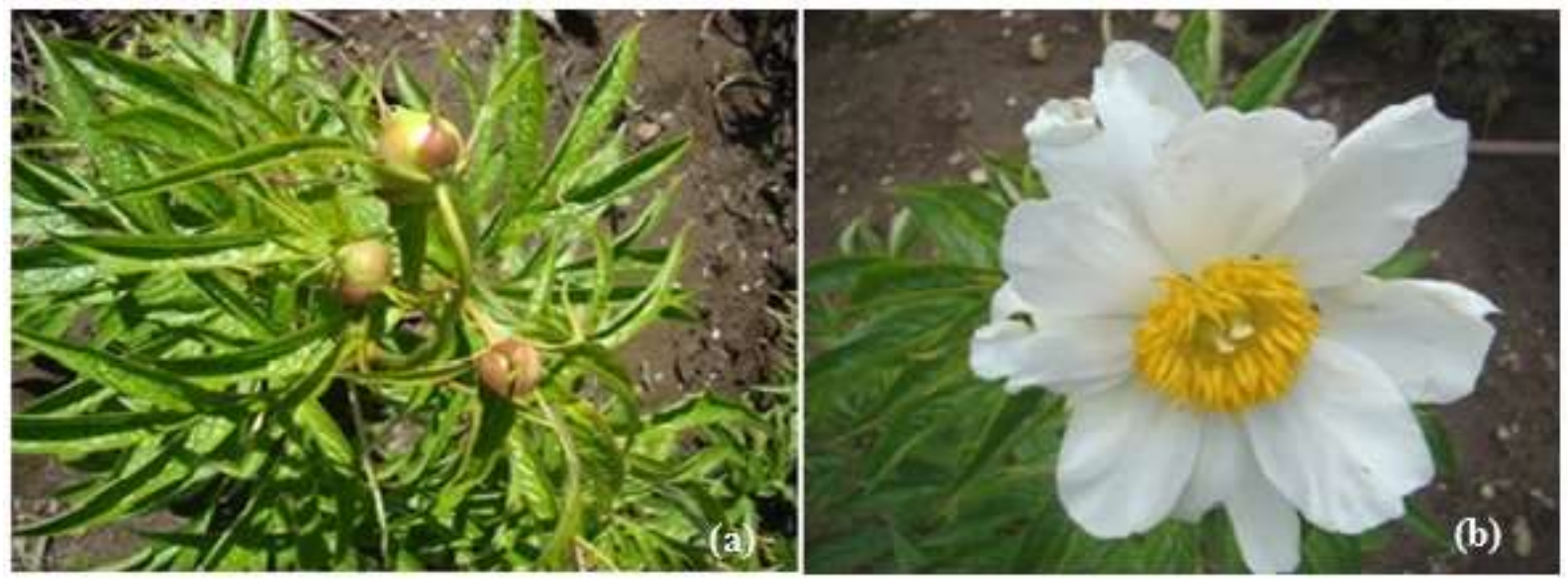

Fig.1. (a) Budding stage \& (b) mature flower with white petals and yellow stamens of $P$. emodi

Paeonia emodi Wall. Ex Royle (Paeoniaceae) is an erect, leafy perennial glabrous herbs, 50-70 cm long, leaves are biternate or ternate, lamina pale, flowers are solitary and axillary. It is largely distributed in North West India, Northern Pakistan, Eastern Afghanistan, China and West Nepal (Deyuan; 2004). It is known from a single locality in China (Hong D.Y., 1997). In India it is located in North -west Himalayas from Kashmir to Garhwal- Kumaon regions of Uttarakhand (Chauhan, 1999; Ismail et al., 2003) at altitude of 1800m asl to $3000 \mathrm{~m}$ asl (Kumar and Rawat; 2011). P. emodi is found in deciduous forests of several oak species and Quercus floribunda, most often on south facing slopes. In Uttarakhand it occurs together with Impatiens thomsonii, I. sulcata, Erigeron multiradiatus, Viola canescens, Trifoliumpratense, Pennisetumflaccidum, Euphorbia peplus and Hemiphragma heterophyllum.

It is commonly known as Chandra or Dhandru or Gundhya in local regions of Uttarakhand. Generally, plant grows on moist place of deciduous mixed forest with Quercus species. The life cycle of plant $P$. emodi starts from mid-February and completed in month of August-September. In the beginning of sprouting plant looks brownish in colour after mature it changes into green colour. The fine foliage is very attractive; flowers are very showy with one row of petals and a large center, and highly ruffled double forms. The colors generally range from white, light pink to magenta and red. The flowering period occurs between April-June. Flowers are solitary, axillary and generally whitish in colour generally pollinated by insects. The plant is self-fertile, suitable for light (sandy), medium (loamy) and heavy (clay) soils and can grow in heavy clay soil. It can grow in semi-shade (light woodland) or no shade and prefers moist soil. Fruits appear in the beginning of monsoon (i.e., July-August and oval shaped-pod with leathery in texture (Rawat et. $a l ., 2010)$ contain black, smooth and shiny seeds with hard seed coat. 


\section{Multipurpose Uses of $P$. emodi}

$P$. emodi is a useful plant found in Western Himalayan region and is used in many ways by the locals and the scientists. It has various physiological activities including prevention of epileptic attacks, for cholera and whooping cough (watt, 1982). The tuber of the plant is highly effective medicine for uterine diseases, blood purifier, colic, bilious, backbone ache, headache, dizziness, vomiting, dropsy, epilepsy and hysteria while the seeds are Purgative (Shinwari et al., 2003; Hamayun et al., 2004; Ahmad \& Sher, 2004). An infusion of the dried flowers is given to control diarrhoea (Chopra et al., 1956).

The haemagglutination activity of the extract was tested against human RBC's and the results showed moderate agglutination effect against all blood groups at the highest concentrations (1:2) and weak activity at a dilution of 1:4. The haemagglutination activity is generally attributed to a group of proteins called as lectins (Benevides et al., 1999). This investigation revealed that $P$. emodi, could be a good source of important plant lectins. Antifungal activity of the crude extract of $P$. emodi was tested against Trichophytonlongi fusus, Candida albicans, Aspergilus flavus, Fusarium solani, and Candida glaberata while various bacteria used in the evaluation of antibacterial activity of this extract included Escherichia coli, Bacillus subtillus, Shigella flexenari, and Staphyllococcus aureus. The crude extract did not display any antimicrobial activity against the fungi and bacteria used in this study. This study was useful in evaluating the toxicity of the extract, which declared it safe to be used (Khan et. al., 2005).

The insecticidal activity of the crude extract was performed against B. pisorum, $T$. castaneum and $R$. dominica and the extract exhibited a moderate (40\%) inhibitory activity against B. pisorum, a weak (20\%) activity against $T$. castaneumand no inhibitory activity against $R$. dominica (Khan et. al., 2005). The interest in the discovery of botanical insecticides as alternatives to the synthetic ones, which possess well-known adverse effects on agro ecological systems, has been increased in the last few decades in integrated pest management program (Pavela, 2004). During the current study, $P$. emodi has shown a moderate insecticidal activity particularly against B. pisorum and thus could be a source of stored product pest control especially if used in higher concentrations than the tested one (Khan et. al., 2005).

The roots and rhizomes are used to cure backache, dropsy and epilepsy and are also used as a tonic, emetic, cathartic, blood purifier and colic while the seeds are purgative (Shinwari et al., 2003). The roots are used for the treatment of headache, dizziness, vomiting and to aid pregnancy (Ahmad and Sher, 2004). The extract from the aerial parts $P$. emodi and its fractions were found to possess significant enzyme inhibition (against urease and -Chymotrypsin) and radical scavenging activities (Khan et al., 2005).

A number of plants, their extracts or their purified active constituents can act as allele-chemicals to other plants and thus could be candidates for application for agricultural purposes (Khan et al., 2002).

\section{Traditional Consumption of $P$. emodi:-}

Whole plant (aerial part) of the species is being used by the local inhabitants of the Garhwal region in Uttarakhand for vegetable preparation. The above ground part of the species is harvested in tender stage and washed with tap water twice to remove soil or sand etc (Fig 2). The plant material is further boiled with water (2:3) (approximate for half an hour) to remove bitterness along with softening it. The water is removed after cooling the material at room temperature followed by washing with tap water 2-3 time. Sometimes, the material is placed in the running water overnight for removing the bitterness. The material is messed properly and dried in room temperature as well as under sunlight. Dried material is used for vegetable preparation. It is observed that vegetable is tasty and observed to be beneficial for diabetic patients. Fresh leaves and petiole extract is given to children suffering from stomach pain (personal conversation with locals). An infusion of the dried flowers is useful in treatment of diarrhea, whooping cough, haemorrhoids and intestinal pain (Gaur, 1999). However, further systematic evaluation of this valuable species is needed. The species has enormous potential, like developing propagation techniques, extraction and evaluation in pre, pro, post processed material for secondary metabolites. 
(a)

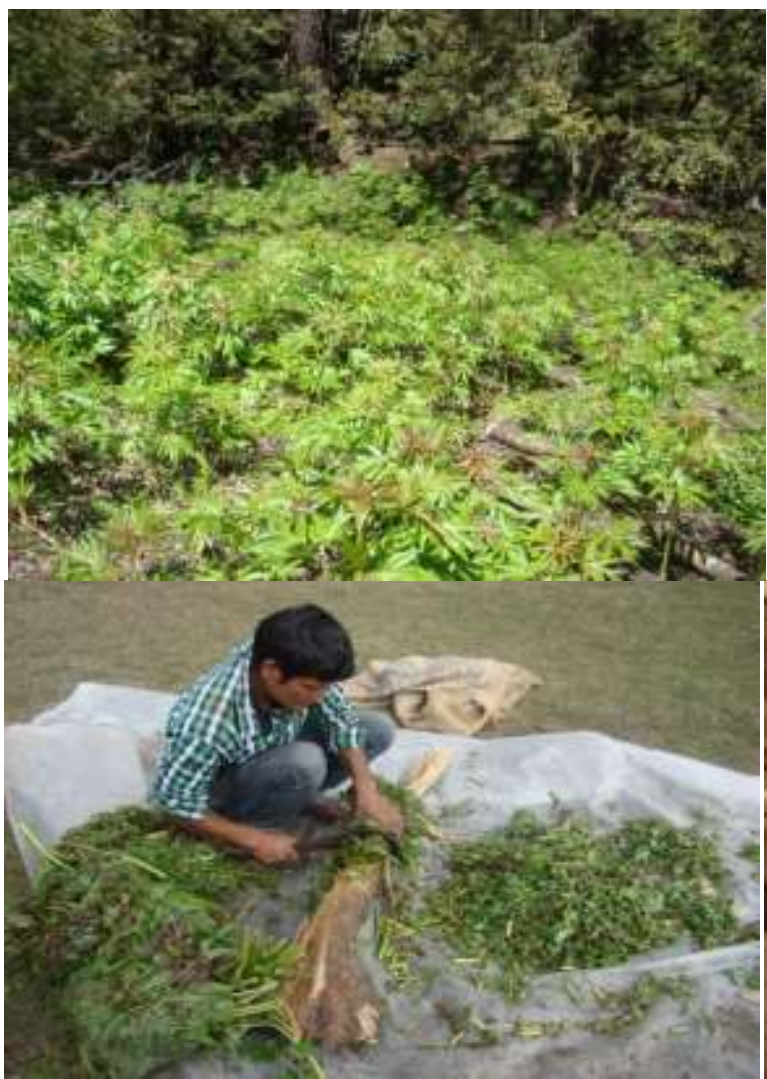

(c)

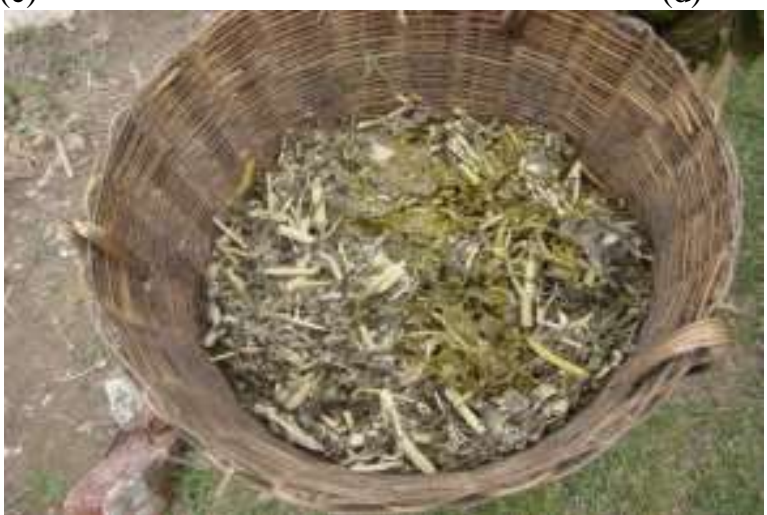

(e) (b)
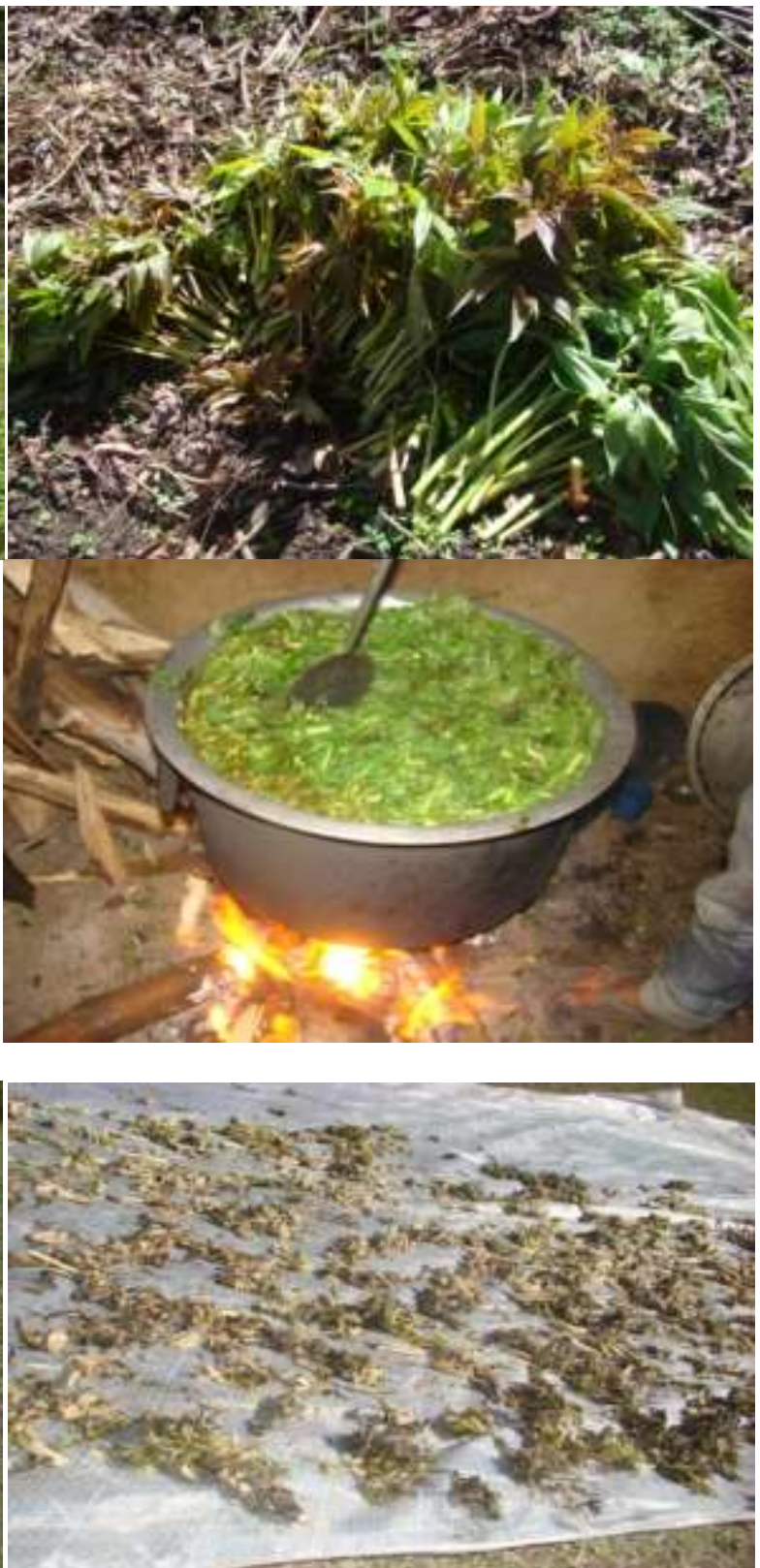

(f)

Fig.2:- Naturally growing plants (a) \& chunks processing of the $P$. emodi (b-f)

\section{Conservation Strategies:-}

The local people are ignorant about the importance of these plants at global level. They collect plants in access quantity and in most cases the whole plant is uprooted. As the people are ignorant about the drying, storing or preservation techniques, which ultimately lead to the wastage of, plant resource. A rare species is not only important at national or local level but also from the point of view of the global biodiversity. Plants in general and medicinal plants in particular in the study area are a finite and precious resource that requires efficient, wise and sustainable management and conservation strategies. Hence, immediate conservation measures are urgently necessary in order to protect the taxa from extinction.

The distance of villages from road head was one of the factors contributing to the decline in the medicinal plant population in their natural habitats. The availability of medicinal plants increased with increase in distance from 
road head and also the peoples' dependence on them. Documentation of the traditional knowledge will help in conservation of knowledge and also opportunity for using it for future training and use. The over exploitation has damaged the flora and is one of the major threats to many plant species. Other threats to the flora are loss of habitat, unplanned collection, deforestation, over grazing, erosion, change of environment, attack of pathogens and effect of introduced taxa. The result of this study will help in promoting sustainable cultivation and implementation in conservation protocol of this species, which are in the verge of extinction in this region.

Various sets of recommendations relating to the conservation of medicinal plants have been developed, such as providing both in-situ and ex-situ conservation. Natural reserves and wild nurseries are typical example to retain the medical efficacy of plants in their natural habitats, while botanical gardens and seed banks/gene banks are important paradigms for ex-situ conservation and future replanting. The geographical distribution and biological characteristics of medicinal plants must be known to guide conservation activities, e.g.to assess whether species conservation should take place in nature or in a nursery.

Besides this, keeping in view the importance and conservation value of $P$. emodi, some conservation strategies need to be taken, i.e. notify the natural populations for the protection of its habit and habitats, detailed study on phenology and morphology with understanding of whole life cycle, sustainable collection of germplasm from natural populations for developing elite generations in future, rehabitation of species before taking any developmental activities, development of large-scale seedlings and their plantation, restrictions in field survey and collection in sensitive areas harvesting natural populations and creation of awareness among the local healers to control over exploitation in natural habitats to maintain its posterity for future. Since policy-makers, scientist and researchers cannot conserve the species without wider support from the local communities and government agencies, particularly the Forest Department, a multi-furious effort is required to conserve the species. The R\&D institutions and universities working on conservation issues need to develop appropriate strategies for sharing their experiences and scientific information for the conservation of this important plant species. Loss of species can have important consequences for the well-being and prosperity of the human population; it reduces the strength and capacity of ecosystem to provide essential goods and services.

\section{Conclusion:-}

P.emodi is multipurpose medicinal plant having great value in Himalayan region. It is a multipurpose herb curing many diseases. People make vegetables, pickle and many bio prospecting natural products from different parts of the plant in high altitude of Himalaya. Rural population of India still depends mainly on the indigenous system of medicine (Uniyal and Shiva, 2005). Many of these ethno medicinal properties have been experimentally proven in different animal models. So it is necessary to explore the traditional knowledge scientifically. Plant population is found in large scale in the forest but presently a high level of anthropogenic pressure has been accrued on the plant. Due to this the plant may be damaged and is under threat. Due to over-harvesting from forests beyond the sustainable limit, there is an urgent need to threat assessment and to develop efficient conservation strategies and propagation protocols of this plant species.

The results obtained from the many studies indicated that $P$. emodi extract might be useful as natural herbicides and could be a source of bioactive agrochemicals. The plant is useful in antifungal activity, antimicrobial activity, phytotoxic activity and many other medicinal uses. The plant has demonstrated activity against various life style disorders. It has been found to possess terpenoids and phenolics as major chemical constituents. A tea made from the dried crushed petals of various peony species has been used as a cough remedy, and as a treatment for haemorrhoids and varicose veins. Ethno-pharmacological claims have been scientifically proven by different authors. Traditional claims have been critically analyzed and discussed in the present review.

Large market demand for medicinal and commercial purposes, overexploitation and extraction by the local villagers from the forest and the endangered status of the species, the study carried out to ensure proper utilization, commercialization and conservation as well as the sustainable development of the species. Due to over-exploitations and over-harvesting there is an urgent need to apply the conservation strategies for this multipurpose wild edible plant for sustainable use and future perspective.

Mountain ecosystems are hot spots for plant conservation efforts because they hold high overall plant diversity as communities replace each other along altitudinal and climatic gradient. This review contributes an enhanced understanding of (1) P. emodi diversity in mountain ecosystem with special reference to Western Himalaya; (2) 
Ethno botanical and ecosystem service values of $P$. emodi within the context of anthropogenic impacts and (3) local and regional plant conservation strategies and priorities.

\section{Acknowledgements:-}

The authors are thankful to Dr. L. S. Rawat, Dr. Arun Jugran, Dr. Prakash Phondani, Dr. Y. M. Bahuguna and Dr. Ajay Maletha, GB Pant National Institute of Himalayan Environment and Sustainable Development (GBPNIHESD), Garhwal Unite, Srinagar Garhwal Uttarakhand.

\section{References:-}

1. Ahmad, M., and Sher, H. (2004). Medicinally important wild plants of Chitral, medicinally important wild plants in view of ethnobotanical study of district Chitral. PMID. 67: 432-440.

2. Ayensu, E. S. (1996). World Medicinal Plant Resources, In conservational for productive agriculture, (VL Chopra and TN Khoshoo, ed.), ICAR, New Delhi, India 11-42.

3. Benevides P.J.C., Sartorelli P., and Kato M.J. (1999). Phenylpropanoids and neolignans from Piper regnellii. Phytochemistry, 52: 339-343.

4. Camp (1998). Biodiversity conservation and prioritization project (BCPP) India Endangered Species project. Conservation assessment and management plan (CAMP) Workshop, 1998 report.

5. Chauhan, N.S. (1999). Medicinal and aromatic plants of Himanchal Pradesh. Indus Publishing Co., New Delhi.

6. Chopra, R.N., Nayar, S.L., and Chopra, I. C. (1956). Glossary of Indian medicinal plants. Council of Scientific and Industrial Research, New Delhi.

7. De-yuan H. (2004). Paeonia (Paeoniaceae) in Xizang (Tibet). Available on-line at: http://flora.huh.harvard.edu/china/novon/hong7-2.htm.

8. Dhar, U. and Samant, S.S. (1993). Endemic plant diversity in the Indian Himalaya I. Rannunculaceae and Paeoniaceae. J. Biogeogr., 20: 659-668.

9. Gaur, R.D. (1999). Flora of the district Garhwal, North-West Himalaya. Trans Media, Srinagar, Garhwal.

10. Gautam, P. L., Raina, R., Srivastava, U., Raychaudhari, S. P. and Singh, B. B. (1998). Prospects of medicinal plants. Proceeding of UHF-IUFRO International workshops on prospects of medicinal plants. India Society of Plant Genetics Resources, New Delhi, India.

11. Gupta, R. and Chadha, K. L. (1995). Medicinal and Aromatic plants research in India. In Advances in horticulture: Medicinal and Aromatic plants. Malhotra Publication House, New Delhi, 11: 1-43.

12. Hamayun, M. (2004). Studies on ethno botany, conservation and plant diversity of Utror and gabral valleys, district Swat, Pakistan (Ph.D. thesis). Islamabad, Pakistan:QuaidAzamUniversity.http://eprints.hec.gov.pk/2411/1/2266.htm,accessedon19 October, 2010.

13. Hong, D.Y. (1997). Notes on Paeonia decomposita Hand.-Mazz.Kew Bulletin 52: 957-963.

14. Hong, D.Y. (2010). Peonies of the world, taxonomy and phytogeography. London: Royal Botanical Gardens Kew; St. Louis: Missouri Botanical Garden. $\mathrm{x}+302$.

15. Ismail, M., Iqbal, Z., Ahmad, B., Zakir, S., and Niaz, U. (2003). Biological and pharmacological properties of two indigenous medicinal plants, Rheum emodi and Paeonia emodi. Pak. J. Biol. Sci., 6: 984-986.

16. Kandari, L.S. (2005). Eco-Physiological and socio-economic studies of some rhizomatous medicinal and aromatic plants species, Ph.D. thesis submitted in Plant physiology, H.N.B. Garhwal University, Srinagar Garhwal, Uttarakhand, India. pp 153.

17. Khan, T., Ahmad, M., Nisar, M., Ahmad, M., Lodhi, M.A., and Choudhary, M.I. (2005). Enzyme inhibition and radical scavenging activities of aerial parts of Paeoniaemodi Wall. (Paeoniaceae). J. Enzyme. Inhib. Med. Chem., 20 (3): 245-249.

18. Khan, S.I.., Nimrod, A.C., Mehrpooya, M., Nitiss, J.L., Walker, L.A., and Clark, A.M. (2002). Antifungal activity of eupolauridine and its action on DNA topoisomerases. Antimicrob. Agents Chemother., 46(6): 17851792.

19. Kumar, A., and Rawat, S. (2011). Bioresources of Uttarakhand: Their conservation and management: List of threatened medicinal plants (CAMP Criteria) from Uttarakhand, pp. 599.

20. Kumar, S., Hassan, S., Dwivedi, A. S., Kukreja, A. K., Sharma, A., Singh, A. K., Sharma, S. and Tewari, R. (2000). Proceeding of the National Seminar on the Frontiers of Research and development in Medicinal Plants, 16-18 September 2000. J. Med. Arom. Plant sci., 22(4A) and 23: (1A), Central Institute of Medicinal and Aromatic Plants (CIMAP), Lucknow, India. 
21. Natesh S. (2000). Biotechnology in the conservation of medicinal and aromatic plants, in K.L. Chadha, P.N. Ravindran, L. Sahajram (Eds), Biotechnology in Horticulture and Plantation Crops, Malhotra Publishing House, New Delhi. pp. 548-561.

22. Rao, V. R., and Arora, R. K. (2004). Rationale for conservation of medicinal plants. In Medicinal plants research in Asia 1: the framework and project work plans, Batugal, P A, Jayashree, K, Lee, S Y and Jeffrey, T O. (eds.) 7-22. Kuala Lumpur, Malaysia: International Plant Genetic Resources Institute (IPGRI).

23. Rawat, B., Gairola, S. and Bhatt, A. (2010). Habitat characteristics and ecological status of Paeonia emodi. Wallich ex Royle: A high value medicinal plant of West Himalaya.

24. Roman P. (2004). Insecticidal Activity of Certain Medicinal Plants. Biological Control of Plant, Medical and Veterinary Pests R. Strang \& H. Kleeberg (eds.) pp 195-198.

25. Samant, S.S., Dhar, U., and Palni, L.M.S. (1998). Medicinal plants of Indian Himalaya: Diversity, distribution and potential values. Gyanodaya Prakashan, Nainital.

26. Shinwari, Z., Khan, A., and Nakaike, T. (2003).Medicinal and other useful plants of district Swat, Pakistan.A. Aziz Communications, Peshawar, Pakistan, pp.139-145.

27. Taous, K., Ahmad, M., Khan, H. and Khan, A.M. (2005). Biological activities of aerial parts of Paeonia emodi Wall, Afr. J. Biotechnol. 4(11): 1313-1316.

28. Uddin, G., Sadat, A., and Siddiqui, B.S. (2013). Phytochemical screening, In vitro antioxidant and antimicrobial activities of the crude fractions of Paeonia emodi Wall. Ex Royle.

29. Uniyal B., and Shiva V. (2005). Traditional knowledge on medicinal plants among rural women of the Garhwal Himalaya. Indian J. Tradt. Know., 4(3): 259-266.

30. Watt G. (1982). Dictionary of economic products of India, Cosmo publication Delhi, India, 6:3. 